\title{
A RELAÇÃO TRABALHO- EDUCAÇÃO NA POLÍTICA SOCIOEDUCATIVA DO ESTADO DO RIO DE JANEIRO
}

\author{
THE RELATIONSHIP WORK-EDUCATION IN THE SOCIO- \\ EDUCATIONAL POLICY OF THE STATE OF RIO DE JANEIRO
}

\author{
LA RELACIÓN TRABAJO-EDUCACIÓN EN LA POLÍTICA \\ SOCIOEDUCATIVA DEL ESTADO DEL RIO DE JANEIRO
}

Carla Ribeiro Santos

\begin{abstract}
Resumo: Neste texto, recorre-se aos conceitos de configuração social, socialização, trajetória e identidade para entender a relação trabalho-educação em espaços que privam e restringem a liberdade juvenil a partir daqueles que ensinam um ofício. Busca-se compreender não apenas as identidades profissionais daqueles que lidam com a educação profissional no sistema socioeducativo, mas também os sentidos de suas ações pedagógicas. Utilizou-se como recurso metodológico a pesquisa documental e bibliográfica. Ao refletir sobre a inter-relação entre trabalho e educação, verifica-se a necessidade de uma formação não apenas voltada para a socialização e para o trabalho, mas, sobretudo, para a humanidade e a emancipação do indivíduo.
\end{abstract}

Palavras-chave: Trabalho e Educação - Sistema Socioeducativo - Identidade.

\begin{abstract}
In this text, the concepts of social configuration, socialization, trajectory and identity are used to understand the work-education relationship in spaces that deprive and restrict youth freedom from those who teach a trade. It seeks to understand not only the professional identities of those who deal with professional education in the socio-educational system, but also the meanings of their pedagogical actions. Documentary and bibliographic research was used as a methodological resource. Reflecting on the interrelationship between work and education, there is a need for training not only for socialization and for work, but, above all for humanity and the emancipation of the individual.
\end{abstract}

Keywords: Work and Education - Socio-Educational System - Identity.

\footnotetext{
${ }^{1}$ Mestra em Educação pela Universidade Federal do Rio de Janeiro (UFRJ). Atua como professora de Língua Portuguesa na Secretaria Municipal de Educação de Mesquita/RJ e na Secretaria de Estado de Educação do Rio de Janeiro. E-mail: carla.ribeiro.ufri@gmail.com
} 
Resumen: En este texto, se recurre a los conceptos de configuración social, socialización, trayectoria e identidad para entender la relación trabajo-educación en espacios que privan y restringen la libertad juvenil a partir de aquellos que enseñan un oficio. Se busca comprender no sólo las identidades profesionales de aquellos que trabajan con la educación profesional en el sistema socioeducativo, sino también los sentidos de sus acciones pedagógicas. Se utilizó como recurso metodológico la investigación documental y bibliográfica. Al reflexionar sobre la interrelación entre trabajo y educación, se verifica la necesidad de una formación no sólo orientada hacia la socialización y el trabajo, sino, sobre todo, para la humanidad y la emancipación del individuo.

Palabras clave: Trabajo. Educación - Sistema Socioeducativo - Identidad.

Liberdade, liberdade!

\section{Introdução}

Neste texto, os versos que compõem a epígrafe enunciam o tema da liberdade uma liberdade que abre as asas sobre a humanidade (TRISTEZA et alli appud ARROYO, 2017). Ao trazer à tona a discussão sobre a relação entre trabalho e educação no sistema privativo e restritivo de liberdade juvenil, cabe a compreensão do conceito de liberdade que se volta para a formação do ser social - a liberdade como possibilidade de "escolher entre alternativas concretas" (NETTO appud GUIMARÃES, 2011, p. 338).

Considera-se, aqui, não apenas a privação e/ou restrição da liberdade no interior do sistema socioeducativo, mas a delimitação da liberdade num campo social, uma vez que o indivíduo - o adolescente infrator - só pode tomar para si, como objeto de sua alternativa, as possibilidades que são determinadas a partir e por meio da complexidade do ser que existe independente dele; o campo de decisões delimita-se, portanto, por meio de um complexo ser: o ser social (LUKÁCS, 2013).

Em outros termos, o conceito de liberdade, empregado ao longo do texto, referese tanto à separação de adolescentes infratores da sociedade mais ampla - a perda de sua liberdade em função de uma socialização imposta pelo cotidiano institucional do Departamento Geral de Ações Socioeducativas, quanto à liberdade de escolha que está circunscrita numa estrutura social específica, pois a liberdade do indivíduo "depende largamente do ponto em que ele nasce e cresce nessa teia humana" (ELIAS, 1994, p. 21).

A partir do século XX, os marcos legais que tratam da política de restrição e privação de liberdade, no Brasil, pressupõem não apenas a liberdade como um direito prioritário, mas também a educação e o trabalho voltado para o público juvenil. Ou seja, há uma 
ênfase na garantia dos direitos fundamentais previstos na Constituição Federal (BRASIL, 1988).

Com a premissa de um Estado de Direito, fundamenta-se a cidadania, a dignidade da pessoa humana e os valores sociais do trabalho com a perspectiva de construção de uma sociedade livre, justa e igualitária (BRASIL, 1988). A voz da igualdade (TRISTEZA et alli appud ARROYO, 2017) ressoa, aqui, como pressuposto da democracia.

É notável, então, que a Constituição Federal possibilita novos rumos para a política pública que se volta para a infância quando impõe em seu artigo $6^{\circ}$, dentre outros, os direitos sociais da educação, do trabalho, da segurança, da proteção à infância e a assistência aos desamparados (BRASIL, 1988).

As bases políticas e ideológicas que orientam a socioeducação², neste século, pressupõem não apenas o desenvolvimento da capacidade produtiva do adolescente infrator, mas, sobretudo, as dimensões humanas, sociais e culturais, visto que o adolescente tem direito a uma vida justa como ressalta Arroyo (2017).

No âmbito legal, a lei 8.069/90 que dispõe sobre o Estatuto da Criança e do Adolescente revoga o Código de Menores de 1979 (BRASIL, 1990) e rompe com a doutrina da situação irregular e com a concepção violenta-punitiva da infância. De acordo com o novo ordenamento jurídico, deve-se zelar pela dignidade da criança e do adolescente $^{3}$ a fim de que sejam cuidados e educados sem a utilização do castigo punitivo ou de quaisquer tratamentos de crueldade ou, ainda, formas de correçãodisciplina (BRASIL, 1990).

Neste sentido, a lei $8.069 / 90$ prevê a igualdade de direitos e a garantia do desenvolvimento pleno em condições de liberdade e de dignidade a esse grupo social específico. O Estatuto da Criança e do Adolescente traz outros sentidos para o campo infanto-juvenil ao enfatizar o caráter protetivo e humano das ações, uma vez que tanto crianças quanto adolescentes não devem receber tratamento de ordem desumana violenta e/ou cruel (BRASIL, 1990).

O Estatuto da Juventude, por sua vez, também dispõe sobre a promoção de uma vida justa e segura a partir da perspectiva da "inclusão, liberdade e participação do jovem na vida em sociedade" (BRASIL, 2013, art. 2º, parágrafo único). É, portanto, assegurado pela lei 12.852/13 a promoção de uma vida digna que ressalte, dentre outros princípios, a autonomia e a emancipação do indivíduo jovem 4 .

No entanto, as concepções de cidadania e de direitos são frágeis quando precisam incluir, socialmente, os considerados violentos e/ou infratores. Ou seja, ainda que pressuponham os adolescentes como sujeitos de direitos e não mais como objetos de intervenção e/ou correção; as concepções jurídico-legais de garantia de direitos e de

2 De acordo com Costa (2006), a socioeducação consiste na educação para o convívio social - para o desenvolvimento pessoal e social do adolescente.

3 Considera-se criança a pessoa até 12 anos de idade incompletos e adolescente aquela que tem entre 12 e 18 anos de idade (BRASIL, 1990).

4 Compreende-se, aqui, o jovem que tem idade entre 15 e 29 anos (BRASIL, 2013), uma vez que a medida socioeducativa pode ser estendida por determinação judicial até os 21 anos de idade como dispõe o Estatuto da Criança e do Adolescente (BRASIL, 1990). 
cidadania acabam por desconsiderar as múltiplas e concretas formas de existência e os diferentes meandros de uma sociedade desigual e diversa.

Nestes termos, a ideia de Estado Democrático de Direito (BRASIL, 1988) acaba por configurar uma dicotomia - ou se é Estado ou se é democrático de Direito - visto que as políticas públicas direcionadas à infância e a adolescência, no Brasil, não foram capazes de garantir condições equitativas de desenvolvimento para o público infantojuvenil em situação de risco social; o que prevaleceu, ao longo dos anos, foi a necessidade de controlar a população pobre e/ou perigosa como enfatizam Rizzini e Pilotti (2011). O Estado, portanto, acaba produzindo indivíduos para o sistema socioeducativo quando não assegura uma efetiva política social.

Este artigo, então, tem como foco a inter-relação entre trabalho e educação no sistema socioeducativo a partir dos sujeitos responsáveis pela formação socioprofissional dessas juventudes infratoras - vulneráveis, desiguais, violentas - e do viés histórico-sociológico, uma vez que a interlocução entre a História e a Sociologia proporciona novos caminhos para as pesquisas educacionais (CHAVES, 2014).

Procura-se refletir sobre a educação profissional ${ }^{5}$ oferecida pelo DEGASE (Departamento Geral de Ações Socioeducativas) ${ }^{6}$ e suas configurações através da interdependência dos sujeitos, já que "tanto os indivíduos quanto a sociedade conjuntamente formada por eles são igualmente desprovidos de objetivo. Nenhum dos dois existe sem o outro" (ELIAS, 1994, p. 18).

Neste sentido, o estudo leva em conta as trajetórias e as respectivas identidades dos instrutores para entender a configuração social (ELIAS, 1980) do DEGASE, bem como as práticas e os saberes que são produzidos ao longo do tempo na instituição, uma vez que as ações individuais estão circunscritas num campo específico: o socioeducativo.

Em outros termos, a ação de um instrutor está inserida numa rede de relações que constitui o próprio DEGASE e, neste caso, a pessoa singular se prende por viver em uma constante dependência funcional de outras pessoas como destaca Elias (1994); há uma rede de funções interdependentes que compõe o sistema socioeducativo.

Trata-se de apreender o movimento que permeia o DEGASE numa perspectiva de ressaltar as ações individuais nas relações sociais como enfatiza Chaves (2014), visto que a estrutura do $\mathrm{DEGASE}^{7}$ "não é a estrutura das pedras isoladas, mas a das relações entre as diferentes pedras com que ela é construída" (ELIAS, 1994, 25).

O sistema socioeducativo é constituído por uma rede de funções que se vincula de forma ininterrupta "formando longas cadeias de atos, para que as ações de cada

\footnotetext{
${ }_{5}$ Para tanto, o recurso metodológico da entrevista com os instrutores do DEGASE foi fundamental para a compreensão dos limites e das possibilidades da educação profissional em espaços que privam e/ou restringem a liberdade do adolescente autor de ato infracional.

${ }^{6}$ O DEGASE é o órgão formulador e executor dos objetivos, das estratégias e das metas da Política Nacional de Atendimento Socioeducativo no Estado do Rio de Janeiro e tem como base os princípios, os conceitos e os critérios estabelecidos pelo Sistema Nacional de Atendimento Socioeducativo - SINASE (RIO DE JANEIRO, 2010).

7 O DEGASE conta com nove unidades de internação e quinze unidades de semiliberdade no Estado do Rio de Janeiro. As medidas socioeducativas são aplicadas em unidades de semiliberdade intituladas CRIAAD (Centro de Recursos Integrados de Atendimento ao Adolescente) e em unidades de internação denominadas CENSE (Centro de Socioeducação) conforme (SANTOS, 2016).
} 
indivíduo cumpram suas finalidades" (ELIAS, 1994, p. 23). E, neste caso, a educação profissional no interior do DEGASE constitui não apenas um meio de socioeducar, mas também de humanizar e/ou emancipar o adolescente que cumpre uma medida de restrição e/ou privação de liberdade.

\title{
Teoria e aspectos metodológicos
}

Neste estudo, ${ }^{8}$ utilizou-se como metodologia a análise de documentos institucionais do Departamento Geral de Ações Socioeducativas, dos marcos legais que regulam e/ou orientam a socioeducação e da bibliografia que trata da temática em questão ao longo da história. Tratou-se de trazer à baila não apenas um estudo documental e bibliográfico, mas também entrevistas semiestruturadas que foram realizadas com sete instrutores de oficinas profissionalizantes do sistema socioeducativo, uma vez que o recurso da entrevista permite como coloca Duarte (2004, p. 215):

\begin{abstract}
Uma espécie de mergulho em profundidade, coletando indícios dos modos como cada um daqueles sujeitos percebe e significa sua realidade e levantando informações consistentes que lhe permitam descrever e compreender a lógica que preside as relações que se estabelecem no interior daquele grupo, o que, em geral é mais difícil obter com outros instrumentos de coleta de dados.
\end{abstract}

Os instrutores convidados para participar da pesquisa de cunho qualitativo foram escolhidos a partir do critério de antiguidade, uma vez que a experiência no sistema socioeducativo poderia conferir significados diversos à função profissional. Além disso, selecionou-se dois grupos de instrutores: os efetivos da instituição DEGASE e os contratados por uma Organização Não-Governamental ou uma empresa privada.

Desta forma, buscou-se uma análise de dois grupos de profissionais - efetivos e contratados - a fim de compreender as práticas e os saberes que são produzidos a partir de suas experiências com a socioeducação, bem como a inter-relação entre trabalho e educação em espaço de privação e restrição de liberdade juvenil. Para efeito de publicação do trabalho, os participantes da pesquisa concordaram com o Termo de Consentimento Livre e Esclarecido e com o uso de seus relatos identificados como pseudônimos, de forma ética, para preservar suas identidades.

A análise das respectivas entrevistas, realizadas com os instrutores, trouxe à tona os conflitos e as contradições do sistema socioeducativo e permitiu o que Duarte (2004) ressalta como possibilidade numa pesquisa qualitativa - o mapeamento tanto das práticas quanto das crenças e dos valores de sistemas que são delimitados. Neste caso, o uso da entrevista possibilitou tanto a compreensão das práticas socioeducativas, quanto dos sentidos que os profissionais atribuem às suas ações pedagógicas e ao próprio DEGASE.

\footnotetext{
8 O estudo a que nos referimos aqui trata-se da pesquisa desenvolvida à título de dissertação de mestrado intitulada "O perfil identitário de instrutores do DEGASE e suas propostas de profissionalizacão nas oficinas: sintonias e dissintonias", desenvolvida na Universidade Federal do Rio de Janeiro, sob a orientação da Prof. ${ }^{a}$ Dr. ${ }^{a}$ Miriam Waidenfeld Chaves (Cf.: SANTOS, 2016).
} 
Em suma, tanto a teoria empregada na pesquisa quanto os recursos metodológicos adotados foram fundamentais para entender a relação trabalho-educação no sistema socioeducativo a partir da experiência dos indivíduos - instrutores. O estudo explicita, portanto, "as estratégias sociais desenvolvidas pelos diferentes atores em função de sua posição e de seus recursos respectivos, individuais, familiares, de grupo" (REVEL, 1998, p. 22) e os desdobramentos da educação profissional no espaço socioeducativo.

\section{Entre marcos legais e operacionais: travessias}

No Brasil, o estudo da socioeducação tem implicado uma compreensão da política pública que se volta para o adolescente como uma prioridade social (BRASIL, 2006). Neste caso, cabe o entendimento tanto de marcos legais que rompem com a questão do menor que por definição "se caracterizava principalmente como criança pobre, totalmente desprotegida moral e materialmente pelos seus pais, seus tutores, o Estado e a sociedade" (LONDOÑO, 1998, p.135) quanto de marcos operacionais que são orientados por projetos educativos (BRASIL, 2006).

Trata-se de trazer à tona uma historiografia que ora apresenta a regulação e o controle infanto-juvenil numa perspectiva punitiva, ora exibe a garantia de direitos e a dimensão socioeducativa. Ou seja, as políticas públicas direcionadas à juventude irregular, desviante, infratora - são formuladas e aplicadas a partir de múltiplas configurações.

Segundo Londoño (1998), a regeneração de adolescentes que cometiam atos indesejáveis era prevista em prisões comuns até o final do século XIX. Desta forma, aqueles que atuavam com discernimento eram recolhidos às casas de correção e eram tratados como criminosos comuns:

Estabelecendo-se que os menores de 14 anos atuavam com discernimento, o código admitia que fossem recolhidos a casas de correção a critério do juiz, até os 17 anos. Isso permitiria que os menores de 17 anos fossem condenados, sendo a prisão comum o destino destas crianças (idem, 1998, p. 130-131).

Pretendia-se a regeneração de adolescentes no espaço de confinamento da prisão - aqui entendida como uma instituição social de caráter total ${ }^{9}$ que tem como premissa a mudança das pessoas à medida que "cada uma é um experimento natural sobre o que se pode fazer ao eu" (GOFFMAN, 2015, p. 22).

Neste sentido, cabe a reflexão de qual era o papel da correção e/ou regeneração no cárcere - quais os sentidos das práticas de encarceramento voltadas para a juventude considerada indesejável e/ou perigosa, uma vez que a prisão promove não apenas o isolamento entre o interno e a sociedade mais ampla, mas também a mutilação do eu como ressalta Goffman (2015).

A prisão, portanto, está longe de oferecer um tratamento humano e regenerativo à população infanto-juvenil desviante, pois além de impor ao indivíduo uma vida

\footnotetext{
9 De acordo com Goffman (2015), a instituição-prisão separa o indivíduo da sociedade impondo-lhe uma vida fechada. O fechamento e seu caráter total "é simbolizado pela barreira à relação social [...] e por proibições à saída que muitas vezes estão incluídas no esquema físico" (idem, p. 16).
} 
dissociada do mundo externo pressupõe a morte da identidade individual - destrói, portanto, com algo precioso à medida que "a perda de identidade é sinônimo de alienação, de sofrimento, de angústia e de morte" como diz Dubar (1997, p. 13). O cárcere acaba, inclusive, por reforçar uma exclusão política e social (AGUIRRE, 2009).

As travessias históricas por que passam crianças e adolescentes - vulneráveis, perigosos - evidenciam tanto a manutenção das desigualdades sociais e o isolamento em instituições fechadas quanto a ausência de uma política social eficaz. No entanto, "quando eles foram gerados, não era esse o plano que a mãe tinha [...] de ver o filho numa unidade fechada" (EMANUEL appud SANTOS, 2016, p. 114).

Essa juventude transgressora aprende a viver, ao longo de seus percursos individuais em ambientes "desunidos e violentos, a viver longe de seus pais, na pobreza ou na miséria, desde a mais tenra idade, para se inventar um estatuto social, para sobreviver em gangues e grupos pouco recomendáveis" (DE MAEYER, 2013, p. 38).

De acordo com Rizzini e Pilotti (2011), várias instituições foram erguidas para amparar e (socio)educar o público infanto-juvenil em situação de vulnerabilidade social - crianças e adolescentes que permaneciam à margem da sociedade. No entanto, verifica-se que ao longo dos séculos, no Brasil, tanto o caráter protetivo quanto o viés educativo previstos pelas instituições não passam de formas de confinamento e controle da juventude desviante.

Há, portanto, uma cultura institucional que prevê o controle e a disciplina dos internos (RIZZINI; PILOTTI, 2011). E, neste caso, embora o atendimento socioeducativo seja orientado pelo paradigma jurídico da proteção integral e pela garantia dos direitos fundamentais apresenta uma nova forma do atendimento atrelada, muitas vezes, "às indispensáveis condições de contenção e segurança" (RIO DE JANEIRO, 2010, p. 8).

Nessa perspectiva, a política da socioeducação também pressupõe o disciplinamento e o controle à medida que enfatiza a necessidade de conter "controlar; comportar" (HOUAISS, 2008, p. 186) o adolescente que cumpre sua medida de restrição e/ou privação de liberdade. A política que tem como "ideal norteador o princípio de formar a pessoa autônoma, o cidadão solidário e o profissional competente" (RIO DE JANEIRO, 2012, p. 372) prevê o regime disciplinar e a privação do "direito de ir e vir" (RIO DE JANEIRO, 2010, p. 8).

Os avanços previstos na Constituição Federal (BRASIL, 1988) e no Estatuto que reconhece crianças e adolescentes como sujeitos de direitos (BRASIL, 1990) e não como meros objetos de vigilância e controle não garantem a redução de medidas privativas de liberdade, pois as mesmas são amplamente utilizadas pelo Judiciário, apesar de todas as recomendações em contrário como ressaltam Rizzini e Pilotti (2011).

Observa-se, então, que a privação de liberdade persiste ao longo da história mesmo quando se legitimam os direitos infanto-juvenis. Pressupõe-se, modernamente, "uma privação com direitos sociais e humanos" (JULIÃO, 2014, p. 22). No entanto, viola-se o próprio direito constitucional quando se priva e/ou restringe a liberdade individual - a liberdade, aqui, está circunscrita num campo de confinamento e/ou isolamento.

Em suma, a configuração socioeducativa não se altera tão-somente por imposições legais, mas, sobretudo, pelas múltiplas mediações dos operadores do sistema 
socioeducativo - e, neste caso, os instrutores têm um importante papel na socialização do adolescente, pois são eles - os operadores - que ressignificam e dão sentido às práticas e aos saberes constituídos num sistema de privação e restrição de liberdade juvenil.

\section{Identidade e socialização profissional de instrutores}

O conceito de identidade utilizado, neste trabalho, refere-se, principalmente, ao uso que se faz dele nas Ciências Sociais. O termo identidade foi amplamente empregado na perspectiva de se compreender o perfil daqueles que ensinam um ofício ${ }^{10}$ no sistema socioeducativo.

A intenção de trazer à tona as dinâmicas identitárias de instrutores, do DEGASE, pressupôs considerar tanto as construções individuais quanto socioprofissionais, uma vez que a identidade não é algo inato - dado a priori - ela é um processo de (re)construção que se dá ao longo da vida. A constituição da forma identitária não depende apenas das próprias orientações e definições individuais, mas também do julgamento dos outros (DUBAR, 1997).

As identidades socioprofissionais se interligam à configurações específicas e, neste caso, a identidade dos instrutores é resultado das contínuas socializações por que passam no sistema socioeducativo como se observa no discurso a seguir: "eu acho que quando eu entrei no DEGASE eu era uma pessoa e hoje eu sou uma pessoa totalmente diferente [...] acho que me tornei mais humano" (DANIEL, appud SANTOS, 2016, p. 103).

Em outras palavras, a análise empreendida leva em conta as trajetórias individuais nas diversas esferas da vida social - de trabalho, de família e de sociabilidade (CERUTTI 1998), já que a socialização profissional do instrutor e a convivência com o adolescente infrator confere mais humanidade à sua prática e o faz refletir sobre suas próprias concepções:

um cachorro, para mim, tinha mais importância que um ser humano. Hoje, o cachorro tem sua importância e o ser humano tem a dele. Eu penso dessa forma hoje [...] você recuperar um ser humano [...] isso eu aprendi dentro do DEGASE. Você lidar com o lado bom e o lado ruim da vida e você valorizar um prato de comida ou a sua mãe, o seu irmão [...] coisas que os garotos não fazem aqui dentro (DANIEL, appud SANTOS, 2016, p. 103).

O trabalho, no sistema socioeducativo, promove a reelaboração da identidade do instrutor ao encontro do que coloca Dubar (1997) quando diz que o emprego condiciona a construção das identidades individuais. A identidade dos indivíduos apresenta, então, múltiplas dimensões de formação e de emprego e seu produto é indissociável das formas relacionais.

Deste modo, não há como entender uma trajetória sem antes construir "os estados sucessivos do campo no qual ela se desenrolou" (BOURDIEU, 2006, p. 190). Eis a importância de se observar os percursos individuais a partir de sua configuração, pois o

${ }^{10}$ Ofício de ator, serigrafista, fotógrafo, garçom, marceneiro, músico, tosador (SANTOS, 2016). 
anúncio de uma visão mais humanizada e diferenciada do sistema socioeducativo é pautada nas experiências sociais:

Eu tive a sorte de ter uns pais que me orientaram de forma diferente. Eu tive um estudo. De repente, isso me orienta de forma diferente; a ter um tratamento diferente. Mas muita gente que vem para cá, vem com a visão de polícia. Então, os agentes [...] eles chamam até de delícia, porque é a polícia do DEGASE (LUCAS appud SANTOS, 2016, p. 95).

Observa-se que o relato do instrutor ratifica a definição de identidade como o produto das diferentes inter-relações sociais, uma vez que é a sua formação humana e sua socialização anterior que permite um outro olhar sobre os adolescentes que se encontram em cumprimento de uma medida socioeducativa. $O$ instrutor provoca, ainda, uma reflexão sobre as condições de desigualdade a partir de sua geração precedente:

\footnotetext{
O meu avô era mulato; o pai da minha mãe era mulato. Talvez a minha bisavó, que aí eu já perdi essa árvore, fosse negra. E aí eu falo: de repente um tataravô de vocês foi negro; foi escravo. Quer dizer, que condição foi dada a esse bisavô; a esse pai e a condição que foi dada pra vocês? A diferença é que talvez eu tenha tido uma condição. Minha família me deu uma condição pra eu estar aqui que vocês não tiveram (LUCAS appud SANTOS, 2016, p. 115).
}

A socioeducação se materializa, portanto, por meio dos diversos processos que foram socialmente construídos ao encontro do que coloca Dubar (1997). Neste sentido, os valores de ordem social e profissional contribuem com as ações pedagógicas dos instrutores do DEGASE - são os seus valores sociais e suas trajetórias individuais que dão sentido ao trabalho desenvolvido com a juventude infratora.

Essa perspectiva relacional possibilita entender o lugar que as oficinas ocupam no contexto da socioeducação - da educação social que, aqui, privilegia a aprendizagem de um ofício para o exercício da cidadania e para a promoção da dignidade humana, pois: "educar é dar dignidade - ou mais exatamente - permitir a cada um reencontrar em si sua dignidade fundamental" (DE MAEYER, 2013, p. 42).

Neste sentido, um instrutor ressalta que o mais importante no sistema socioeducativo é trabalhar a inclusão social e os aspectos da cidadania, pois a oficina é também um espaço de produção de saberes. De acordo com o instrutor é fundamental mostrar para o adolescente infrator que ele tem capacidade de fazer outras coisas. Em suas palavras: "Para ser profissional em qualquer atividade e, principalmente, na minha atividade o garoto tem que estudar. Para mim, profissionalizar tem que ter um estudo; tem que ter um conhecimento [...] profissional tem que estudar" (PEDRO appud SANTOS, 2016, p. 116).

O instrutor, aqui, reconhece a importância do conhecimento para aqueles que se encontram internados no DEGASE a partir de sua concepção profissional e de sua identidade como instrutor-ator, pois em seu entendimento o que realmente importa: "é ser cidadão. Ele pode ser cidadão trabalhando com qualquer coisa, inclusive como ator" (PEDRO appud SANTOS, 2016, p. 116).

Desta forma, o indivíduo - instrutor - está investido na rede socioeducativa pela e na formação à procura de saberes como diz Dubar (1997). Eis porque alguns instrutores reconhecem a sua função educativa no DEGASE e se definem, inclusive, como professores: 
Eu me considero um professor, porque eu acho que o professor não é só você chegar aqui e botar uma mesa no centro. Professor de banho e tosa: pegar um cachorro e mostrar como dá banho e tosa. Ser professor é você preparar aquele adolescente, aquela pessoa para vida. Ser professor é você orientar ele para vida fora daqui do sistema. É mostrar para ele que ele pode aprender com o banho e tosa e com a experiência e pegando outras experiências de vida que ele pode entrar aqui e mudar (DANIEL appud SANTOS, 2016, p. 80).

Diante do exposto, observa-se que o instrutor compreende o trabalho numa acepção diferente de emprego; o trabalho representa a possibilidade de produção e reprodução da própria vida ao encontro do que diz Frigotto (2015). É, portanto, na emergência de se educar para o social num espaço de privação e restrição de liberdade que outro instrutor transcende a mera instrução mecânica: "Nós estamos trabalhando com a alma do ser humano; nós estamos trabalhando o espírito dele; com aquilo que ele tem lá dentro que vai favorecê-lo até nas escolhas profissionais" (JOSÉ appud SANTOS, 2016, p. 81).

Fica evidente na fala do instrutor que sua função, no DEGASE, é permeada por uma perspectiva humanitária à medida que a formação para cidadania acarreta em resgate da individualidade do ser humano e se distancia da "noção mercantil de cidadão produtivo" (FRIGOTTO; CIAVATTA, 2003, p. 57).

\section{Educação para o trabalho e dimensão socioeducativa}

Procura-se, neste item, caracterizar a socioeducação como uma modalidade da ação educativa que se destina a preparar o adolescente infrator para a convivência em sociedade "no marco da legalidade e da moralidade socialmente aceitas, como forma de assegurar sua efetiva e plena socialização" (COSTA, 2006, p. 10). Trata-se de refletir sobre o processo socioeducativo a partir da política de formação para o trabalho que é posta em prática nas oficinas do Departamento Geral de Ações Socioeducativas.

No final da década de 1990, materializa-se a educação para o trabalho no DEGASE por meio da criação de um centro profissionalizante. Contudo, o reconhecimento deste centro de capacitação profissional como unidade do sistema socioeducativo ocorre tãosomente, no ano de 2008, com o Centro de Capacitação Profissional (RIO DE JANEIRO, 2015).

Com a criação do Centro de Capacitação Profissional, a política pública da socioeducação passa a ser redefinida a partir de uma dupla dimensão - educar para o social e educar para o trabalho - como prevê o Sistema Nacional de Atendimento Socioeducativo quando ressalta que o sistema deve possibilitar aos adolescentes não apenas o desenvolvimento de competências e habilidades básicas e competências interrelacionais, mas também a competência produtiva para uma possível inserção no mercado de trabalho e para a convivência numa sociedade moderna (BRASIL, 2006).

Desta forma, os princípios norteadores da política socioeducativa pressupõem a relação trabalho-educação e uma configuração social que possibilite a consolidação das leis que tratam dos direitos e da proteção à criança e ao adolescente. $E$, neste sentido, o todo - DEGASE - é constituído de uma estrutura complexa de indivíduos interdependentes como destaca Elias (1994). 
Em outros termos, embora o sistema socioeducativo não seja harmonioso e ainda carregue marcas de um outro tempo (RIZZINI; PILOTTI, 2011), é visível o esforço coletivo de instrutores que têm como função socioeducar e ensinar um ofício. É, portanto, na configuração de um trabalho integrado que se dá por meio de uma "rede de funções que as pessoas desempenham umas em relação a outras" (ELIAS, 1994, p. 23) que denominamos a sociedade - DEGASE.

Esses vínculos de interdependência transcendem, inclusive, o contexto socioeducativo, visto que a política de aplicação das medidas socioeducativas está ligada às demais políticas públicas sociais e protetivas como prevê o princípio da incompletude institucional quando diz que os programas socioeducativos e sua rede de serviços:

Demanda a efetiva participação dos sistemas e políticas da educação, saúde, trabalho, previdência social, assistência social, cultura, esporte, lazer, segurança pública, entre outras, para a efetivação da proteção integral de que são destinatários todos adolescentes (BRASIL, 2006, p. 23).

Nestes termos, a dinâmica da socioeducação e da proteção integral de adolescentes pressupõe uma teia de relações que está para além da instituição DEGASE. Há, inclusive, um ordenamento jurídico que enfatiza o cuidado e os direitos da criança e do adolescente:

É dever da família, da sociedade e do Estado assegurar à criança e ao adolescente, com absoluta prioridade, o direito à vida, à saúde, à alimentação, à educação, ao lazer, à profissionalização, à cultura, à dignidade, ao respeito, à liberdade e à convivência familiar e comunitária, além de colocá-los a salvo de toda forma de negligência, discriminação, exploração, violência, crueldade e opressão (BRASIL, 1988 , art. $227^{\circ}$.

Contudo, a história da assistência no Brasil traz à tona muitos adolescentes desvalidos - órfãos, abandonados, descuidados e/ou infratores. Ou seja, ao longo do tempo, é notável tanto crianças quanto adolescentes que são desprovidos de valor e de proteção de alguém (RIZZINI; PILOTTI, 2011).

As instituições, então, são criadas a fim de dar conta dos filhos do Estado como ressaltam Rizzini e Pilotti (2011) e o DEGASE, portanto, tem a função de educar e/ou reeducar pelo e para o trabalho parte dessa juventude negligenciada: a infratora. De acordo com o Plano Político Institucional do DEGASE: "Na educação para o trabalho, o adolescente vai aprender para trabalhar. Na educação pelo trabalho, o educando vai trabalhar para aprender. Essas duas ferramentas pedagógicas devem ser usadas de forma convergente e complementar" (RIO DE JANEIRO, 2012, p. 380).

Nesse contexto, percebe-se que cabe ao DEGASE a superação de "modelos correcional-repressivo, assistencial-repositivo" (RIO DE JANEIRO, 2010, p. 5) até então utilizados, uma vez que suas ações estão em consonância com as políticas sociais protetivas e emancipadoras. No entanto, a socioeducação e o ensino de um ofício são implementados em espaços que privam e/ou restringem a liberdade individual do adolescente infrator conforme o enunciado:

No início do ano passado, eu montei uma peça e eu comentei com eles, assim, que tudo era possível, basta eles quererem e muitos falaram assim: a gente não consegue, porque nós estamos presos [...] e eu falei assim: não! Estão presos hoje, 
mas não estão presos eternamente e se vocês quiserem nós vamos tentar (PEDRO appud SANTOS, 2016, p. 113).

Convém, então, compreender a própria concepção de educação sócio-profissional que vislumbra a ideia do "respeito e da garantia dos direitos fundamentais dos adolescentes e jovens autores de atos infracionais" (RIO DE JANEIRO, 2012, p. 371), pois a liberdade é um direito elementar previsto no artigo $5^{\circ}$ da Constituição Federal (BRASIL, 1988). Eis, aqui, a importância de:

\begin{abstract}
Identificar e hierarquizar as aprendizagens para lhes dar um sentido: para que elas possam lhe oferecer possibilidades de escolha com conhecimento de causa; para que a faculdade de escolher reencontre seu campo de ação, a saber o euaprisionado, mas aprisionado por um certo tempo apenas (DE MAEYER, 2013, p. 39).
\end{abstract}

Observa-se, portanto, a partir do próprio campo socioeducativo e de suas regras que o sistema de atendimento ao adolescente infrator é constituído de contradições e tensões que delimitam as ações individuais e, neste sentido, o fazer cotidiano do instrutor está inserido numa estrutura que tem suas próprias especificidades tanto em relação as formas de sociabilidade - as relações entre os indivíduos - quanto em relação às formas de socioeducar, uma vez que "há em cada campo princípios de organização que são próprios deste campo" (BOURDIEU; CHARTIER, 2011, p. 89).

Verifica-se, então, que cada oficina do DEGASE tem uma configuração própria; embora a proposta de uma formação socioprofissional seja o fio condutor das ações socioeducativas. Deste modo, buscou-se compreender o movimento que perpassa por cada configuração nas oficinas do DEGASE e quais as dificuldades que instrutores encontram em suas práticas cotidianas e, sobretudo, ao lidar com adolescentes de menor valor social, pois "a maioria desses meninos não tem formação básica, fundamental; ou vão trabalhar com obra ou vão para o tráfico, simplesmente isso" (JOSÉ appud SANTOS, 2016, p. 106).

Cabe pensar o percurso entre o mundo da educação e o mundo do trabalho a partir do discurso anunciado pelo instrutor - os caminhos e os descaminhos por que atravessa a juventude como destaca Costa (2006), já que muitos adolescentes ingressam "no mundo do trabalho sem a educação formal completa ou com apenas uma formação reduzida, portanto, sem absolutamente nenhuma capacitação específica" (idem, p. 91). Neste sentido,

É muito difícil você, hoje, colocar um garoto na rua e falar assim: esse garoto está aqui; ele vai voltar pra rua; ele vai trabalhar. É muito difícil! Então, a maior dificuldade, pra mim, hoje, dentro do DEGASE, como professor de banho e tosa é você colocar esse garoto na sociedade de novo. É a maior dificuldade (DANIEL appud SANTOS, 2016, p. 117).

Enfim, é preciso entender que a inter-relação entre trabalho e educação no sistema socioeducativo pressupõe outros movimentos de formação para cidadania movimentos que levem em conta que as trajetórias individuais estão circunscritas num campo de possibilidades (VELHO, 2003) que é delimitado pelo social. 


\section{Considerações Finais}

No artigo, em questão, buscou-se refletir sobre a formação para o trabalho e a educação para a formação do ser social - aspectos constitutivos da política socioeducativa no Estado do Rio de Janeiro.

A análise da identidade profissional de instrutores do DEGASE e de suas ações pedagógicas possibilitou a compreensão, ainda que parcial, da configuração socioeducativa que tem como incumbência promover uma educação para o convívio em sociedade "no sentido, de criar espaços e condições para que os adolescentes e jovens em conflito com a lei [...] possam desenvolver as competências pessoais, relacionais, produtivas e cognitivas" (RIO DE JANEIRO, 2010, p. 5).

Em outros termos, procurou-se pensar na cultura institucional do Departamento Geral de Ações Socioeducativas na sociedade atual - sociedade essa que não demonstra "um real interesse sobre o que efetivamente ocorre dentro do cárcere ou em uma unidade socioeducativa; sobre a qualidade dos serviços prestados" (JULIÃO, 2014, p. 31).

O estudo empreendido evidencia que o sistema socioeducativo não é apenas constituído pela inter-relação entre trabalho e educação, mas também por uma rede de funções interdependentes. Neste sentido, embora os dispositivos legais orientem as práticas sócio-educacionais; são as ações dos indivíduos que estão circunscritos no espaço do DEGASE que, efetivamente, dão sentido a configuração socioeducativa.

Deste modo, a socioeducação anunciada pelos operadores do sistema socioeducativo - os instrutores - traz à tona o papel formativo da educação profissional que não se limita à aprendizagem de uma técnica, mas que funciona como um instrumento de emancipação social.

Contudo, a formação que prevê um novo tipo de cidadão voltado para o mercado (RIO DE JANEIRO, 2015), seja como sujeito empreendedor, seja como sujeito de consumo corre o risco de "atender aos mecanismos sociais e políticos da reprodução das relações sociais fundadas na estrutura de dominação de classe" (SOUZA, 2015, p. $55)$.

Eis, portanto, a importância de ser o trabalho um instrumento educativo e, principalmente, de formação para humanidade e para a liberdade; pois muitos adolescentes chegam ao sistema socioeducativo marcados por processos de desumanização e exclusão:

\footnotetext{
O grande erro do sistema brasileiro, no trabalho dirigido ao adolescente em conflito com a lei, é que ele não priva o educando apenas de liberdade. Ele o priva, infelizmente, do respeito, da dignidade, da individualidade, da integridade física, psicológica e moral. As revoltas, as rebeliões e as hostilidades e agressões que ocorrem nas unidades educativas, portanto, não são de caráter proativo. Elas são, na realidade, uma reação dos adolescentes a uma violência maior cometida pelo sistema contra eles (COSTA, 2006, p. 56).
}

Parte-se, então, do pressuposto de uma nova cultura socioeducativa que leve em consideração o todo social e a "condição humana sobre todas as coisas" (JULIÃO, 2014, p. 16), uma vez que os instrutores participantes do estudo - também operadores do sistema socioeducativo - reconhecem que grande parte da juventude infratora vem de 
uma classe vulnerável e/ou excluída que sobrevive, historicamente, sob condições adversas e que é con(formada) para uma socialização desigual como coloca Souza (2015).

Eis, portanto, a urgência de saberes e práticas que entendam a igualdade como parte fundamental de um projeto emancipador de socioeducação e que outras concepções possibilitem novas configurações sociais e políticas.

\section{Referências}

AGUIRRE, Carlos. Cárcere e Sociedade na América Latina 1800-1940. In: MAIA, C.N.; SÁ NETO, Flávio de; COSTA, Marcos; BRETAS, Marcos Luiz. História das Prisões no Brasil. Rio de Janeiro: Rocco, 2009. p. 35-77.

ARROYO, Miguel G. Passageiros da noite: do trabalho para a EJA: itinerários pelo direito a uma vida justa. Petrópolis: RJ: Vozes, 2017. 294 p.

BOURDIEU. Pierre. A ilusão biográfica. In: FERREIRA, Marieta de Moraes; AMADO, Janaína (org.). Usos e abusos da história oral. Rio de Janeiro. FGV, 2006. p. 183-191.

BOURDIEU, Pierre; CHARTIER, Roger. Estruturas e indivíduo. In: BOURDIEU, Pierre; CHARTIER, Roger. $\mathbf{O}$ sociólogo e o historiador. Tradução de Guilherme João de Freitas Teixeira. Belo Horizonte: Autêntica, 2011. p. 45-134.

BRASIL. Código de Menores. Lei Federal n 6.697, de 10 de outubro de 1979. Brasília, 1979.

BRASIL. Constituição da República Federativa do Brasil. Brasília, 1988.

BRASIL. Estatuto da Criança e do Adolescente. Lei Federal n 8.069/90, de 13 de julho de 1990. Brasília, 1990.

BRASIL. Estatuto da Juventude. Lei Federal nº 12.852, de 05 de agosto de 2013. Brasília, 2013.

BRASIL. Sistema Nacional de Atendimento Socioeducativo (SINASE). Brasília, SEDH/CONANDA, 2006.

CERUTTI, Simona. Processo e experiência: indivíduos, grupos e identidades em Turim no século XVII. In: Jogos de Escalas: a experiência da microanálise. Rio de Janeiro: Editora Fundação Getúlio Vargas, 1998. p. 173-201.

CHAVES, Miriam Waidenfeld. História da educação escolar e Sociologia: uma relação promissora. Educação em Revista, Belo Horizonte, vol. 30, n. 2, abril-junho, 2014. p. 95 116.

COSTA. Antônio Carlos Gomes da. Socioeducação: Estrutura e Funcionamento da Comunidade Educativa. Brasília: Secretaria Especial dos Direitos Humanos, 2006. 156 p.

DE MAEYER, Marc. Educação na prisão não é mera atividade. Revista Educação \& Realidade. Porto Alegre. Educação em Prisões, v. 38, n. 1, jan./mar, 2013. p. 33-49. 
DUARTE, Rosália. Entrevistas em pesquisas qualitativas. Educar em Revista. Curitiba. n. 24. 2004. p. 213-225.

DUBAR, Claude. A socialização: construção das identidades sociais e profissionais Tradução de Annette Pierrette R. Botelho e Estela Pinto Ribeiro Lamas. Porto: Porto Editora, 1997. 240 p.

ELIAS, Norbert. O conceito de configuração. In: ELIAS, Norbert. Introdução à sociologia. Lisboa: Edições 70, 1980, p. 140-145.

ELIAS, Norbert. A sociedade dos indivíduos. Rio de Janeiro: Zahar, 1994. 201 p.

FRIGOTTO, Gaudêncio; CIAVATTA, Maria. Educar o trabalhador cidadão produtivo ou o ser humano emancipado? Trabalho, Educação e Saúde, vol. 1, n.1, 2003, p. 45-60.

FRIGOTTO, Gaudêncio. Contexto e sentido ontológico, epistemológico e político da inversão da relação educação e trabalho para trabalho e educação. Revista Contemporânea de Educação, vol. 10, n. 20, julho/dezembro, 2015, p. 228-248.

GOFFMAN, Erving. Manicômios prisões e conventos. Tradução de Dante Moreira Leite. 9 ed. São Paulo: Perspectiva, 2015. p. 312.

GUIMARÃES. Cátia Corrêa. Entrevista: José Paulo Netto. Trab. Educ. Saúde, Rio de Janeiro, vol.9, n.2. jul./out. 2011, p. 333-340.

JULIÃO, Elionaldo F. Política de execução penal no Brasil: questões, avanços e perspectivas. In: JULIÃO, Elionaldo F. \& SANTA RITA, Rosângela Peixoto. Privação de Liberdade: desafios para a política de Direitos Humanos. Jundiaí: Paco Editorial, 2014. p. 11-39.

LONDOÑO, Fernando Torres. A origem do Conceito Menor. In: DEL PRIORE. História da Criança no Brasil. São Paulo: Contexto, 1998. p. 129-145.

LUKÁCS, G. Para uma ontologia do ser social II. São Paulo: Boitempo, 2013. 856 p.

REVEL, Jacques. Microanálise e construção do social. Rio de Janeiro, Fundação Getúlio Vargas, 1998. p. 15-38.

RIO DE JANEIRO (Estado). Decreto 42.715 de 23 de novembro de 2010. Plano de Atendimento Socioeducativo do Governo do Estado do Rio de Janeiro PASE/DEGASE. D. O. do Estado do Rio de Janeiro. Parte I; Poder Executivo Ano XXXVI; No 213 de 24 de novembro de 2010. p. 1-10.

RIO DE JANEIRO (Estado). Plano Político Institucional - PPI/DEGASE. Departamento Geral de Ações Socioeducativas, Rio de Janeiro, 2012. p. 368-383.

RIO DE JANEIRO (Estado). Projeto Político Pedagógico - CECAP (Centro de Capacitação Profissional). Departamento Geral de Ações Socioeducativas (DEGASE), 2015. p. 1-25.

RIZZINI, Irene; PILOTTI, Francisco. A arte de governar crianças: a história das políticas sociais, da legislação e da assistência à infância no Brasil. 3.ed. São Paulo: Cortez, 2011.

SANTOS, Carla Ribeiro. 0 perfil identitário de instrutores do DEGASE e suas propostas de profissionalização nas oficinas: sintonias e dissintonias. Rio de Janeiro: 2016. 143 p. 
Dissertação (Mestrado em Educação) - Programa de Pós-Graduação em Educação da Faculdade de Educação, Universidade Federal do Rio de Janeiro.

SOUZA, José dos Santos. A formação do trabalhador no contexto da reconfiguração do trabalho, da produção e dos mecanismos de mediação do conflito de classe. Revista Contemporânea de Educação, vol. 10, n. 20, julho/dezembro, 2015. p. 273-290.

VELHO, Gilberto. Trajetória individual e campo de possibilidades. In: VELHO, Gilberto. Projeto e Metamorfose. Antropologia das sociedades complexas. Rio de Janeiro: Jorge Zahar Editora, 2003. p. 31-48. 